
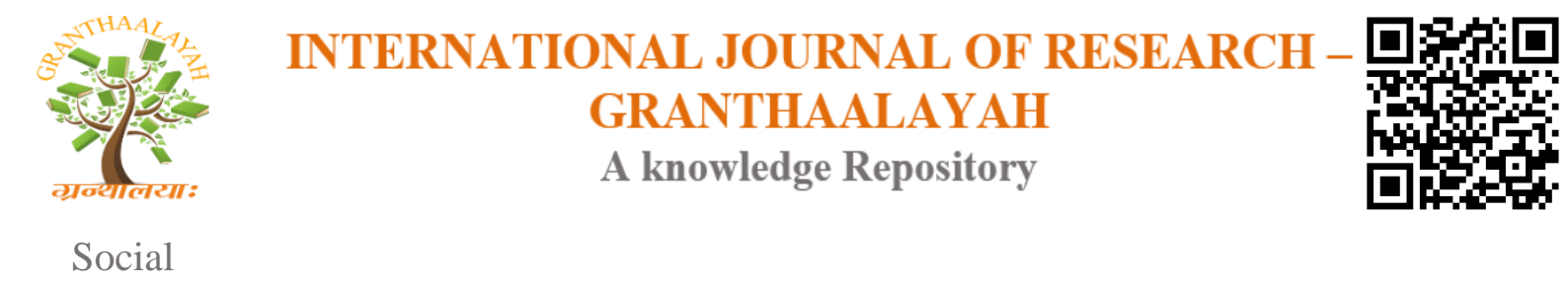

\title{
A PHENOMENOLOGICAL STUDY ON THE EXPERIENCES OF CARERS OF THE MENTALLY ILL ON A MENTAL HEALTH FACILITY IN THE PHILIPPINES
}

\author{
Cristina Marie Alissandra V. Redubla, RPm ${ }^{* 1}$, Ginbert Permejo Cuaton ${ }^{2}$ \\ ${ }^{* 1}$ Registered Psychometrician, Schistosomiasis Hospital, Palo, Leyte, Philippines \\ ${ }^{2}$ Faculty-Researcher, Leyte Normal University, Tacloban City, Leyte, Philippines
}

\begin{abstract}
In the Philippines, mental illness remains a stigmatized, under-researched topic. Few studies on mental health are available, and at present, there is scant literature concerning the experiences of people living with and giving care to mentally ill peoples. This qualitative study aims to help families, mental health professionals, and the general community, gain an understanding of the experiences of caregivers and the challenges they face in sustaining their roles. Phenomenological method was employed for this research to explore the experiences of caregivers of the mentally ill patients in a Mental Health Facility in Leyte, Philippines. The primary data were collected through in-depth interviews with carers/caregivers/relatives of five (5) mentally ill persons. Library and internet desk research in its related literature were also employed. General findings of the study showed that caring for a mentally ill is burdensome. Data analysis revealed four superordinate themes under the experiences of caregivers, these consists of 1) caregiving difficulties, 2) various emotional reactions, 3) attitude towards the situation, and 4) positive caregiving experiences. Several support programs and services such as provision of mental health education and counseling regarding facts about the illness, its treatment and management, and leniency on watcher requirements during hospital admission are recommended to facilitate better caregiving experience of carers of the mentally ill.
\end{abstract}

Keywords: Caregiving Experience; Mental Illness; Caregiver; Philippines; Phenomenological Research.

Cite This Article: Cristina Marie Alissandra V. Redubla RPm, and Ginbert Permejo Cuaton. (2019). "A PHENOMENOLOGICAL STUDY ON THE EXPERIENCES OF CARERS OF THE MENTALLY ILL ON A MENTAL HEALTH FACILITY IN THE PHILIPPINES.” International Journal of Research - Granthaalayah, 7(3), 38-47.

\section{Introduction}

WONCA and $\mathrm{WHO}^{1}$ reported that in every four (4) people in the world, one (1) will be affected by a neurological or mental disorder. There are currently around 450 million people who suffer from such conditions, placing mental disorders among the top causes of disability worldwide. ${ }^{2}$ 
Mental illness remains a stigmatized, under-researched topic in the Philippines. Few studies on the area of mental health are available, and at present, there is scant literature concerning the experiences of people living with and giving care to mentally ill peoples. Even more scarce are the accounts of families and caregivers who mainly provide for their needs.

It is reported that one (1) in five (5) Filipinos will suffer from mental illness. ${ }^{3}$ Currently, there are 700 psychiatrists and an estimated 1,000 psychiatric nurses for a population of 100,000 who can cater to the needs of these people. There is only a total of 50 outpatient care and 32 inpatient care mental health facilities in the country that provides primary interventions such as drug administration, psycho-diagnosis \& therapy. ${ }^{4}$

Despite the glaring statistics, few resources can be found on the caregiving experiences of people living with mentally ill persons. This lack of knowledge is seen to be a result of the strong belief in spiritual and otherworldly causes of physical and mental problems widespread throughout the Philippines and the Western Pacific Region. This archaic belief system amplifies and reinforces the reliance of Filipinos on traditional and folk healers since they offer a cheaper and accessible alternative to mental health professionals. ${ }^{5}$ The early stages of the professionalization of counselors and psychologists in the country do not provide much help, thus, making mental health services inaccessible and momentarily prohibitive.

Given these, this research aims to help families, mental health practitioners, and society as a whole, to explore the lived experiences of primary caregivers and to recognize the things that help them sustain their caring role. Specifically, this research tries to:

1) Explore and describe the experiences of caregivers of the mentally ill.

2) Formulate recommendations to support caregivers and families of mentally ill.

\section{Materials and Methods}

This study utilized the Four Stages in Caregiving Experience as the theoretical framework that helped in the analysis and presentation of findings. This model was theorized by a sociologist named David Karp. ${ }^{7}$ Karp based his findings through his interviews with many family members about their experiences in the process of caregiving. ${ }^{8}$ Karp argues that there are four interpretive stages which correspond to the paths that caregivers and mentally ill people take in the caregiving process.

1) Experiencing Emotional Anomie- This characterizes the first few moments in the shared experience of the mentally ill and family caregivers. Family members may feel extremely puzzled and confused by the person's behavior and have no idea how to respond, emotionally or behaviorally.

2) Getting a Diagnosis- Caregivers struggle to empathize with their sick family member after a diagnosis has been made. They often believe that combining both medical treatment and utmost care to their family member will solve the problem.

3) Perceiving Illness Permanency- Once a clear picture of the family member's chronic illness is seen, the kinder emotions of concern and sympathy usually recede replaced by deeper feelings of anger and frustration. These hostile emotional reactions are likely to surface if caregivers perceive that their ill family member does not take responsibility for their recovery. 
4) Acceptance- In the end, some caregivers may admit that the illness is beyond their control. Recognizing this can release family members of guilt by validating their withdrawal feelings.

Research Locale: This study was conducted from January to March 2018 at the Acute Crisis Intervention Service (ACIS) Unit of Schistosomiasis Hospital (SH) formerly Schistosomiasis Control and Research Hospital (SCRH) in Palo, province of Leyte in the Eastern Visayas region of the Philippines. ACIS is an immediate short-term psychological care which aims to assist an individual under a crisis situation to restore stability or equilibrium to their biopsychosocial functioning. Drug administration, psycho-diagnosis \& therapy are the primary interventions for SH-ACIS inpatients.

Research Design: Phenomenological method was employed for this research to explore the experiences of caregivers of the mentally ill patients in the Acute Crisis Intervention Service. The primary data were collected through in-depth interviews with caregivers or relatives of a mentally ill person who visit the said hospital. Library and internet desk research in its related literature were also employed.

The phenomenological method was use because this study is more concerned with first hand descriptions of caregivers than in resolving why caregivers of mentally ill persons experience life the way they do. Phenomenological research differs from other modes of qualitative inquiry because it attempts to understand the essence of a phenomenon from the perspective of participants who have experienced it. ${ }^{9,} 10,11$ The focus is not on the participants themselves or the world that they inhabit, but rather on the meaning or essence of the interrelationship between the two. ${ }^{12}$ Thus, this phenomenological research seek to uncover the essence of the experiences of caregivers of the mentally ill patients at the Acute Crisis Intervention Service (ACIS) Unit of the Schistosomiasis Hospital in Palo, Philippines.

The authors utilized, adapted, and customized the questionnaire used by Monyaluoe ${ }^{13}$ and translated it to the local language of Waray-Waray in Leyte, Philippines for a better understanding of the participants. The questions were semi-structured followed by specific questions that probed deeper into their experiences in order to gain more valuable information. The interview and dialogue were also conducted in Waray-Waray. A pilot interview was first conducted to test the questionnaire.

Data Collection and Sampling: Purposive sampling, considered as the most important kind of non-probability sampling ${ }^{14}$, was used to identify the primary participants. The authors selected the sample based on their judgement and the purpose of the research ${ }^{15}, 16,17,18$ looking for those who "have had experiences relating to the phenomenon to be researched"19. Relatives, family members and/or significant others of admitted ACIS patients were directly approached and asked to participate in the study. These interviewees are the primary unit of analysis, ${ }^{20}$ with their 'informed consent'. ${ }^{21,22,23}$

To ensure ethical research, authors declare that the procedures employed in this study were in accordance with the ethical standards of the responsible committee on human experimentation (institutional and national) and with the Helsinki Declaration of 1975, as revised in 2000. The 
authors also made use of informed consent. ${ }^{24,} 25$ Bailey cautions that deception may be counterproductive. ${ }^{21}$ However, not asking the leading central research question (given under the next heading) is not regarded as deception. ${ }^{25}$ The authors developed a specific Informed Consent Agreement to gain the informed consent from participants, namely, a) that they are participating in the research, (b) the purpose of the research (without stating the central research question), c) the procedures of the research, d) the risks and benefits of the research, e) the voluntary nature of research participation, and $f$ ) the procedures used to protect confidentiality. ${ }^{22,20,25,23}$

There is no right answer to the question of the sample size in studies using phenomenological method. Boyd said that two (2) to ten (10) participants or research subjects are sufficient to reach saturation ${ }^{26}$, and Creswell recommended "long interviews with up to 10 people" for a phenomenological study, ${ }^{27}$ hence, a sample size of 5 relatives and caregivers of mentally ill patients were asked and voluntarily participated in this study. To qualify as a participant, each participant swore that they were the principal caregiver of the patient i.e. someone who spends most of his time taking care of the patient for at least 1 year. The family members interviewed were parents, specifically mothers (3), spouse (1), and child (1) of the mentally ill person. All participants were adults between 30 to 60 years old.

Data Analysis: Each interview lasted for about 30 minutes to 1 hour, all the while ensuring that there were no interruptions. The non-verbal reactions and observation during the interviews were also noted to blend with other field notes and recorded data. The recordings were transcribed verbatim and translated from Waray-Waray to English. In the process of transcription ${ }^{28}$, the participants' words were recorded as close as possible. The process helped capture the thematic arrangement of concerns for each participant. The clusters were then assigned a name to represent the superordinate themes.

\section{Results and Discussions}

Presented here are the results of the study includes a description of the participants and their experiences as the primary caregivers of their mentally ill family member. Four major themes were drawn out from the final analysis of the caregiving experiences.

Most of the participants were females, $80 \%$ (4/5), and $80 \%$ of them were between the age of 30 to 65 years (4/5). Eighty percent $(80 \%)$ of the participants did not reach college level (4/5) and only 2 of them have a gainful occupation. All participants claimed to have been taking care of their patients for at least 2 years. On the other hand, 3 out of 5 mentally ill patients suffered from schizophrenia while 2 were diagnosed with Bipolar 1 Disorder.

\section{Theme 1: Caregiving Difficulties}

\section{Internal Struggles}

Caregivers report high levels of burden and stress concerning patient behaviors. They struggle with taking care of the patient by forcing and pleading them to comply with treatment. Most patients only take their medication e.g. neuroleptic drugs when admitted at the inpatient ACIS Ward. A few months or even weeks after discharge, patients would willfully discontinue taking these medicines and even refuse to go to their monthly consultation. As reported, all patients of these 
caregivers had already relapsed at least twice over the past 3 years. Caregivers carry the weight of these recurring problems, resulting in declaring the situation as a "big cross to carry" for their family. As one caregiver put it "Only very few men can handle her (wife) situation". Carers do their best to persuade their ill family member to comply with the treatment by reminding or even admonishing them. They sacrifice a lot for the sake of these patients by working for longer hours and enduring the lengthy process of seeking financial aid from charitable institutions or government agencies e.g. DSWD (Department of Social Work and Development). They also experience impaired family functioning since they tend to prioritize the needs of the sick family member first before the needs of others. It is very difficult for them to sustain the provision of medicines due to lack of financial capacity considering that most of them have no regular income. Another hindering factor in helping patients gain insight is the irony that caregivers themselves lack the appropriate knowledge to take care of the patient. They sometimes associate the behavioral oddities of the mentally ill as caused by supernatural forces or of physical cause. Caregivers admit to seeking help and treatment from faith healers prior to pursuing medical intervention. Oftentimes, hospitalization is sought when symptoms worsen such as patient already tried to harm himself, another person, or has caused havoc in their family or community. Even when they seek hospitalization, carers still lack the understanding of the nature, causes, and treatment of their family member's illness. This leads them to be surprised and confused on how to respond to their patient's behavior.

\section{External Struggles}

The following situations have caused the greatest external problems for them: patient's poor insight, strangers teasing and making fun of the patient; counterproductive patient behavior and; patient misunderstanding with watchers. These circumstances contribute negatively to the fast recovery of patients. The lack of patient watcher (caregiver inside the Ward) is regarded as the greatest difficulty upon hospitalization. There is an absence or lack of a qualified same-sex watcher within the family or that no one simply volunteers for fear of their safety. Thus, caregivers resort to hiring an able-bodied watcher for 14 days which adds to their financial burden. Oftentimes, watchers are forced to take care of the patient and set all other obligations aside.

\section{Theme 2: Various Emotional Reactions}

Most of the participants have trouble processing everything they are going through and somehow questions their integrity as a family or whether there is something wrong with them. Initial reactions of caregivers upon noticing that patients had relapsed are difficulty in sleeping, stress, fear of danger, helplessness, irritation, impatience, and an overwhelming sadness. Caregivers feel heavily burdened and obliged to take care of their patients even if it means enduring the pain and shame of repetitive hospitalization. Few of the participants also reported disappointment towards other family members' uncaring and dismissive attitude towards the patient.

\section{Putting the Blame on the Patient}

Caregivers feel angry towards their patient for not complying with medications, not heeding the advice of professionals, taking on vices and being generally defiant and stubborn with treatment. Most of the carers expressed frustration and disappointment towards their mentally ill patient for not helping themselves and not taking responsibility for their actions. 


\section{Putting the Blame on Other Factors}

Caregivers recognize that there are things beyond their control, thus, they identified issues that have shifted the focus away from the patient. Caregivers believe that work is a notorious illnesscausing or relapse-causing factor in mental illness. Lastly, primary caregivers feel that the rest of the family members do not support the steady recovery of their patients thereby resulting in more relapse.

\section{Giving up and Surrendering}

Thoughts of abandoning their patient and forsaking all obligations are not a far-fetched idea. The previous caregiver of one patient has in fact abandoned all responsibility and left the patient to the care of another family member. They consider their situation as too much to bear and they feel an overwhelming tiredness and brain-drain from absorbing all information. One caregiver considered placing their sick in a homecare and wanted to ask forgiveness from God because as she said, "...the love is probably gone, I only have pity for her". Also, conditional love has surfaced in the findings.

\section{Theme 3: Attitude towards the Situation}

\section{Kind Gestures towards the Mentally III}

Participants become more understanding, compromising and accommodating. Caregivers understand that showing hostility and criticisms towards patients do not help alleviate the symptoms, in fact, it aggravates their symptoms. They tend to reprimand their patient less often, provide a caring and supportive environment and promote healthy habits for the patient to emulate. In explaining the complexity of the situation, one respondent said while crying: "...taking care of my son is like holding an egg. I treat him like a baby and I am very careful and sensitive to his needs."

\section{Taking extreme measures}

Despite the kindness and considerate attitude of caregivers, they also report going great lengths to ensure the steady recovery of their mentally ill family member. They monitor everything about the patient especially when it comes to their compliance with medication. They make sure nothing goes wrong, vigilantly observing patient activities and avoiding things that could worsen the situation. Participant's paranoia towards the situation is a means of exhausting all possible means of treatment and perseverance to provide the needs of the patients.

\section{Apprehension for the Future}

Carers are unsure whether to expect a full recovery or an endless relapse of the patient which is why they constantly check patient activities such as vices, unhealthy behavior, and employment conditions. Most importantly, respondents fear that no one will take over their caring roles when they die. They fear that other family members do not understand the patient's condition well enough to shoulder the responsibility. The poor economic conditions of the family resulting in the inability to provide for the medical needs of the patients is also one of their greatest fear. 


\section{Theme 4: Positive Caregiving Experiences}

Respondents claim to receive support such as prayers from church members, support from friends and community members, assistance from in-laws and other members of the family, and lack of discrimination from the public. They also expressed appreciation to the hospital staff in helping the patients recuperate during their stay in the mental health facility. Finally, caregivers experience joy when they see their patients responding positively towards treatment. Witnessing their sick family member become easy to deal with, having good insight, helping provide for the family and showing care towards others, gives them hope and optimism.

This study provides a culturally sound and in-depth understanding of the phenomenon of caring for mentally ill people in the Philippines, with an emphasis on analyzing their experiences in their caring roles. The richness of data in this study provided support that caregiving is indeed a difficult and burdensome responsibility while discounting some claims of researches on the topic.

Similar to the findings of Ayuurebobi Ae-Ngibise et. al., ${ }^{29}$ participants described various caregiving difficulties and emotional reactions towards caring for their mentally ill family member. The lack of knowledge and information on how to take care of their patients also adds to their stress and anxiety. They respond by attributing this illness to otherworldly and physical causes which do not relate in any way to the facts about the disease. Insufficiency of information constitutes an obstacle to families in taking care of their mentally ill member. ${ }^{30,31}$

Participants also experience various physical and emotional reactions that can be classified as forms of emotional disturbances ${ }^{32}$. Meanwhile, other reported emotional and behavioral changes may already qualify as an anxiety disorder due to symptoms such as difficulty in sleeping, negative thought insertion, agitation and over-vigilance. According to the Stages of Grief $\mathrm{Model}^{6}$ and the Four Stages in the Caregiving Experience ${ }^{7}$, caregivers experience the following: 1) difficulty comprehending or accepting the state of their patient or family situation to the point of idleness; 2) hate towards the patient for their noncompliance to treatment; 3) agreeing, compromising, and accommodating the wishes of the patient in order to negotiate terms where both parties will be happy; 4) questioning their efforts and experiencing extreme sadness, hopelessness, exhaustion and other symptoms associated with emotional problems (depression); and 5) finally after going through all four stages, caregivers come to understand the whole situation and accept wholeheartedly the patient's condition.

High expressed emotion inside the family also surfaced as a behavior to be avoided to reduce the challenging behavior of patients. ${ }^{33}$ Most caregivers have come to realize that being harsh and imposing to their mentally ill family member do not always result to better compliance. Showing less hostility and criticism is their approach to effectively manage and facilitate the treatment of their family member.

Contrary to the findings of Caqueo-Urízar et al., ${ }^{34}$ participants in the study who have been taking care of their mentally ill family members for longer years show a more positive attitude towards their patients and the illnesses. Caregivers tend to focus and involve themselves more on the concerns of the patient while putting all other responsibilities at bay. ${ }^{35}$ The theory on help-seeking 
behavior is also strengthened by the findings that the participants, though lacking in education, promote a strong drug compliance and acceptance thereby resulting in a low help-seeking attitude. The professional and institutional services they have received count as essential resources in fulfilling their roles as primary caregivers ${ }^{13}$. The kindness of the people around them and the lack of discrimination has helped these families flourish and become unrestricted in giving everything they can for their patients.

\section{Conclusions and Recommendations}

The researchers conclude that caring for a mentally ill family member is indeed a burdensome experience. This research revealed the interplay of various factors affecting the caregiving process and recommends further research related to the coping strategies and support needed by caregivers providing an in-depth understanding of the phenomenon. Consistent with the objectives of this study, the following recommendations have been proposed to effectively support caregivers of the mentally ill.

Mental health institutions should strengthen their health education and counseling services to families to help them gain sufficient understanding and awareness of the psychiatric diagnosis of the patient. Mental health education should be intensified to minimize stigma brought about by various psychiatric conditions, thereby increasing family \& community involvement in patient's therapy. At the same time, patient and family counseling should be a continuous endeavor to improve compliance with the medication regimen and decrease patient's involvement in vices which pose as a huge risk factor for recovery.

Further studies on coping and needed support services and programs for carers of the mentally ill are also recommended.

\section{Acknowledgements}

The authors are grateful to the research participants for their generous help in giving their time and sharing their experiences as caregivers of people with mental illness. Due credit is also given to the Schistosomiasis Hospital for allowing the conduct of this research in their institution. Any misrepresentations is unintended and is solely the authors' responsibility.

\section{References}

[1] World Organization of Family Doctors (WONCA) and World Health Organization (WHO). 2008. Integrating Mental Health Into Primary Care: A Global Perspective. Retrieved from https://www.who.int/mental_health/policy/services/integratingmhintoprimarycare/en/

[2] WHO. The World Health Report, Mental Health: New Understanding, New Hope. Geneva: WHO (2001, October 4). Retrieved from http://www.who.int/whr/2001/media_centre/press_release/en/

[3] Magtubo, C.A. (2016, September 2). Mental Health in the Philippines: By the numbers. Retrieved from: https://today.mims.com/mental-health-in-the-philippines--by-the-numbers

[4] WHO. Mental Health Atlas 2017. Geneva: World Health Organization; 2018. Licence: CC BYNC-SA 3.0 IGO. [Cited 11 January 2019] available from http://apps.who.int/iris/bitstream/handle/10665/272735/9789241514019-eng.pdf?ua=1 
[5] Tuliao, A. (2014), Mental Health Help Seeking Among Filipinos: A Review of the Literature. Faculty Publications, Department of Psychology. 792.

[6] Bolden, L. A. (2007). A Review of on grief and grieving: Finding the meaning of grief through the five stages of Loss. Counseling and Values, 51(3), 235-237. doi:10.1002/j.2161007x.2007.tb00081.

[7] Anusha K, Bogaraju, Anand, Usha L. (2017). Helpseeking behaviors in the relatives of mentally ill persons at a tertiary care hospital. Indian J Soc Psychiatry 2017; 33:250-5. doi: 10.4103/09719962.214597

[8] Karp, D. \& Tanarugsachock, V. (2000). Mental illness, caregiving, and emotion management. Qual Health Res 2000 10: 6. doi: 10.1177/104973200129118219

[9] Eddles-Hirsch, K. (2015). Phenomenology and Educational Research. International Journal of Advanced Research, Vol. 3, Issue 8, 251-260.

[10] Christensen L. B., Johnson, R. B., \& Turner, L. A. (2010). Research methods, design and analysis (11 ${ }^{\text {th }}$ Ed.). Boston, MA: Allyn \& Bacon.

[11] Khan, S. (2014) Qualitative research method- phenomenology. Asian Social Science; Vol. 10: 21; 2014. doi:10.5539/ass. v10n21p298

[12] Merriam, S. (2014). Qualitative Research: A Guide to Design and Implementation.

[13] Monyaluoe M., Mvandaba M., Plessis E.D., \& Koen M.P. (2014). Experiences of families living with a mentally ill family member. J Psychiatry 17: 131. doi:10.4172/Psychiatry.1000131

[14] Welman, J. C., \& Kruger, S. J. (1999). Research methodology for the business and administrative sciences. Johannesburg, South Africa: International Thompson.

[15] Babbie, E. (1995). The practice of social research (7th ed.). Belmont, CA: Wadsworth.

[16] Greig, A., \& Taylor, J. (1999). Doing research with children. London: Sage.

[17] Schwandt, T. A. (1997). Qualitative inquiry: A dictionary of terms. Thousand Oaks, CA: Sage.

[18] Groenewald, T. (2004). A phenomenological design illustrated. International Journal of Qualitative Methods, pp. 42-55.

[19] Kruger, D. (1988). An introduction to phenomenological psychology (2nd ed.). Cape Town, South Africa: Juta.

[20] Bless, C., \& Higson-Smith, C. (2000). Fundamentals of social research methods, an African perspective (3rd ed.). Lansdowne, South Africa: Juta.

[21] Bailey, C.A. (1996). A guide to field research. Thousand Oaks, CA: Pine Forge.

[22] Arksey, H., \& Knight, P. (1999). Interviewing for social scientists. London: Sage.

[23] Street, A. (1998). In/forming inside nursing: Ethical dilemmas in critical research. In G. Shacklock \& J. Smyth (Eds.), Being reflective in critical educational and social research. London: Falmer.

[24] Holloway, I. (1997). Basic concepts for qualitative research. Oxford: Blackwell Science.

[25] Kvale, S. (1996). Interviews: An introduction to qualitative research interviewing. Thousand Oaks, CA: Sage.

[26] Boyd, C.O. (2001). Phenomenology the method. In P.L. Munhall (Ed.), Nursing research: A qualitative perspective (3rd. ed., pp. 93-122). Sudbury, MA: Jones and Bartlett.

[27] Creswell, J. W. (1998). Qualitative inquiry and research design: Choosing among five traditions. Thousand Oaks, CA: Sage.

[28] Smith, J. A., \& Osborn, M. (2008). Interpretative Phenomenological Analysis. Doing Social Psychology Research, 229-254. doi10.10029780470776278.ch10

[29] Ayuurebobi Ae-Ngibise, K., et. al., (2015). The experience of caregivers of people living with serious mental disorders: A study from rural Ghana, Global Health Action, 8:1, 26957, DOI: 10.3402/gha.v8.26957

[30] Lakeman R. (2008). Family and carer participation in mental health care: perspectives of consumers and carers in hospital and home care settings. J Psychiatr Ment Health Nurs 2008; 15:203-11. doi:10.1111/j.1365-2850.2007.01213.x 
[31] Wang, Y., Hsieh S., Hsieh, R. (2017). Family carers' experiences in striving for medical care and finding their solutions for family members with mental illnesses. International Journal of Medical and Health Sciences 11:5, 2017. doi: 10.4103/0971-9962.214597

[32] Wrosch, C., Amir, E., \& Miller, G. E. (2011). Goal adjustment capacities, coping, and subjective well-being: The sample case of caregiving for a family member with mental illness. Journal of Personality and Social Psychology, 100(5), 934-946. doi:10.1037/a0022873

[33] Endley, L., \& Berry, K. (2011). Increasing awareness of expressed emotion in schizophrenia: an evaluation of a staff training session. Journal of Psychiatric and Mental Health Nursing, 18(3), 277280. doi:10.1111/j.1365-2850.2010.01683.x

[34] Caqueo-Urízar et al. (2011). Attitudes and burden in relatives of patients with schizophrenia in a middle income country. BMC Family Practice 2011 12:101. doi.org/10.1186/1471-2296-12-101

[35] Iseselo M. et al. (2016). The psychosocial problems of families caring for relatives with mental illnesses and their coping strategies: A qualitative urban based study in Dares Salaam, Tanzania. BMC Psychiatry, Vol 16:146doi.org/10.1186/s12888-016-0857-y

\footnotetext{
*Corresponding author.

E-mail address: zandraredubla@yahoo.com/cuatonginbert@ gmail.com
} 